\title{
A New Palpation Sign for the Diagnosis of Atypical Forms of Acute Appendicitis (Children and Women of Childbearing Age)
}

\section{Vitezslav Marek ( $\sim$ vitezslav.marek@gmail.com )}

Comenius University in Bratislava: Univerzita Komenskeho v Bratislave https://orcid.org/0000-00015106-2007

\section{Roman Záhorec}

Comenius University in Bratislava Faculty of Medicine: Univerzita Komenskeho v Bratislave Lekarska fakulta

\section{Stefan Durdík}

Comenius University in Bratislava Faculty of Medicine: Univerzita Komenskeho v Bratislave Lekarska fakulta

\section{Research article}

Keywords: atypical forms of acute appendicitis, new palpation sign

Posted Date: May 5th, 2021

DOl: https://doi.org/10.21203/rs.3.rs-462131/v1

License: (c) (1) This work is licensed under a Creative Commons Attribution 4.0 International License. Read Full License

Version of Record: A version of this preprint was published at Journal of Surgery and Research on January 1st, 2022. See the published version at https://doi.org/10.26502/jsr.10020205. 


\section{Abstract}

\section{Background}

Even today, the diagnosis of acute appendicitis (AA) is still problematic. Here, we offer a new palpation sign for the diagnosis of AA. In this study, we evaluate the efficacy of the sign for the diagnosis of atypical forms of AA (i.e., in children and women of childbearing age).

\section{Methods}

We have retrospectively analysed 2245 patients - children (aged 0-12), men (aged 12-18) and women of childbearing age (aged 12-45) with suspected AA, 401 of whom underwent surgery. Patients were divided into one of three age categories and, based on clinical data and histological findings, were defined as either false negative, false positive, or positive. Confirmed positive AA was defined based on histological findings, and confirmed negative AA was defined by histological findings as well as on clinical follow-up. Pearson's correlation analysis was used for the assessment of the correlation between the patient's gender, age as well as their clinical and histological findings.

\section{Results}

Based on these statistical results, we came to the following results. In children (aged 0-12, male/female) and in women of childbearing age (aged 12-45), we observed $14(3,46 \%)$ false negative clinical findings for the palpation sign. In children and women of childbearing age, we observed a higher percentage of palpation sign positivity compared to false positivity. The new palpation sign minimizes unindicated revisions of the abdominal cavity, serves as a reliable indicator for surgery and is suitable for the diagnosis of AA in atypical forms (i.e., in children and women of childbearing age) with a sensitivity of $95,57 \%$, a specificity of $95,78 \%$, a positive predictive value of $67,86 \%$, a negative predictive value of $99,50 \%$, a positive likelihood ratio of 24,28 , a negative likelihood ratio of 0,05 and an accuracy of $95,9 \%$. The negative appendectomy rate in women of childbearing age was $9.22 \%$ and in children $6,72 \%$.

\section{Conclusion}

We conclude that the new palpation sign is effective $(r>0.95)$ for the diagnosis of atypical forms of AA (i.e., in children and women of childbearing age). It is aimed principally at the medical practitioners in different parts of the world and in a state of emergency (Covid-19 pandemic, wars, etc.) where the diagnostic facilities and technological resources are limited.

\section{Background}

Acute appendicitis (AA) is defined as a non-specific bacterial inflammation of the worm-like appendage of the colon. The doyen of Czechoslovakian surgery, academician Arnold Jirásek, defines acute appendicitis as "an insidious, unpredictable, and dangerous disease which causes diagnostic difficulties with its unpredictable onset and course" [1]. In the classic form of AA with typical symptoms, diagnosis is 
relatively simple, while atypical forms of AA result in diagnostic difficulties $[2,3,4,5]$. Patients with the most common atypical form of AA include children and women of childbearing age.

The course of AA in a woman of childbearing age can be confusing, causing the diagnostic difficulties. This results from an atypical course of pain, where the original Volkovich-Kocher sign is suppressed and a colic pain in the abdomen or right adnexa is dominant. The anatomical proximity of the appendix to the internal genitalia causes frequent confusion of AA with gynaecological diseases (e.g., an ectopic pregnancy, pelvic inflammatory disease, or complicated ovarian cyst) $[6,7,8]$. AA is more common in men than in women (3:2) [9]. Despite these statistical data, the lifetime risk of an acute appendectomy in women is higher than in men (2:1), which can be explained by the more demanding diagnostic procedures required for female AA, with a higher number of preventive, negative appendectomies [10]. Delayed AA diagnosis in women of childbearing age may lead to perforation of the appendix, resulting in tragic consequences regarding sterility $[11,12,13]$.

Overall, $1-8 \%$ of children presenting with abdominal pain have AA [14]. AA is rare condition in children under 6 years of age and is often diagnosed with delay in this age group [15]. Even with the development and availability of sophisticated imaging techniques, these methods have not eliminated complications in cases of paediatric $A A$, such as perforation, abscess formation, or diffuse peritonitis. A recent study showed a significant increase of perforation in relation with age as follows: $100 \%<1$ year; $100 \% 1-2$ years; $83,3 \% 2-3$ years; $71,4 \% 3-4$ years; $78,6 \% 4-5$ years and $47,3 \% 5$ years $[16,17,18,19]$.

The reason for this is the delayed diagnosis of the disease. This delay is caused by its non-specific clinical manifestation, which is often covered up by other non-specific childhood diseases, as well as the child's inability to describe and specify their own health problems $[20,21]$. The rate of incorrect diagnosis concerning AA ranges from $28-57 \%$ in 2 - to 12 -year-old children, and is almost $100 \%$ in children under 2 years of age [22].

Anamnesis and clinical examination remain the basic diagnostic approaches, and allow approximately $84 \%$ of patients with AA to be diagnosed [23]. The aim of this study is to offer surgeons a new palpation sign as a reliable tool for the diagnosis of atypical forms of AA (i.e., in children and women of childbearing age) and an effective indicator for surgical intervention.

\section{Methods}

In this study, with the use of the new palpation sign that has been in practice for 12 years (2006-2018), we retrospectively analysed 2245 patients - children (aged 0-12), men (aged 12-18) and women of childbearing age (aged 12-45) who were examined for suspected AA at the Department of Oncological Surgery, St. Elizabeth Hospital, Medical School of Comenius University in Bratislava, Slovak Republic, and the Department of General Surgery, Liptovsky Mikulas Hospital, Slovak Republic. Of these patients, 401 of required surgery $($ Table 1,2$)$ 
Table 1

Total number of patients examined $(n=2245)$.

\begin{tabular}{|llll|}
\hline Characteristics of Patients & $\mathbf{0 - 1 2}$ Years & $\mathbf{1 2 - 1 8}$ Years & $\mathbf{1 8 - 4 5}$ Years \\
\hline Sex & & & \\
\hline Male & $158(7.03 \%)$ & $446(19.86 \%)$ & 0 \\
\hline Female & $236(10.51 \%)$ & $570(25.38 \%)$ & $835(37.19 \%)$ \\
\hline
\end{tabular}

Table 2

Total number of patients operated upon $(n=401)$.

\begin{tabular}{|llll|}
\hline Characteristics of Patients & $\mathbf{0 - 1 2}$ Years & $\mathbf{1 2 - 1 8}$ Years & $\mathbf{1 8 - 4 5}$ Years \\
\hline Sex & & & \\
\hline Male & $55(13.71 \%)$ & $119(29.67 \%)$ & 0 \\
\hline Female & $35(8.72 \%)$ & $42(10.47 \%)$ & $150(37.40 \%)$ \\
\hline
\end{tabular}

Inclusion criteria: patients- children (aged 0-12, male/female), men (aged 12-18) and women of childbearing age (aged 12-45) with clinically diagnosed AA (using the new palpation sign) without symptoms of diffuse peritonitis.

Exclusion criteria: patients after appendectomy, patients with a history of inflammatory bowel disease (Crohn's disease or ulcerative colitis), clinical symptoms lasting more than $48 \mathrm{~h}$, and men aged 18-45.

\section{New Palpation Sign}

The new palpation sign (described by Vitezslav Marek in 2020) belongs to the group of viscerosomatic palpation signs.

\section{Description of the New Palpation Sign}

"Clinical examinations of patients have been performed by experienced surgeons (residents) familiarized with the principle of the new palpation sign. We place the patient on his/her left side with their knees bent. In children, we palpate the abdomen with our right hand. The thumb is located in the lumbar region and pushes into the abdominal cavity. Using 2 to 4 fingers, the surgeon pushes the abdominal wall of the right hypogastrium into the abdominal cavity. If they notice pulsation of the iliac artery, the sign is considered negative, i.e., this sign excludes AA. If a deep palpation induces a contracture of the abdominal wall which does not allow the pulsation of the iliac arteries to be felt, even when the child is exhaling, the sign is considered positive, i.e., there is a high probability of acute appendicitis (Fig. 1)" [24].

"We examine the abdomen of a woman of childbearing age bimanually. The thumbs press on the lumbar region, pushing it into the abdominal cavity. Using the fingers of both hands, the surgeon pushes the abdominal wall of the right hypogastrium into the abdominal cavity. With pulsation of the iliac artery during palpation, the sign is considered negative, i.e., it excludes AA. Attention should be paid to 
examining the internal genitalia of the woman. If deep palpation induces a contracture of the abdominal wall that does not allow the pulsation of the iliac artery to be felt, the sign is considered positive, i.e., there is high probability of acute appendicitis (Fig. 2)" [24].

\section{Statistical Analysis}

We performed Pearson correlation analysis to determine the correlation between the distribution of the patients' gender and age, as well as their clinical and histological findings.

\section{Results}

The demographic data for patients included the following: age, gender, clinical data (new palpation sign), and histological findings (phlegmonous appendicitis, gangrenous appendicitis, negative histological finding). Confirmed positive AA was defined based on histological findings, and confirmed negative AA was defined by histological findings as well as on clinical follow-up.

Based on age, patients were divided into one of three age categories $(0-12,12-18$, and $18-45)$. Based on the correlation between clinical and histological findings, the clinical examination was defined as either a false negative, false positive, or positive (Table 3 ). 
Table 3

Clinical findings of the patients that were operated upon $(n=401)$.

\begin{tabular}{|c|c|c|c|c|c|}
\hline $\begin{array}{l}\text { Characteristics } \\
\text { of Patients }\end{array}$ & $0-12$ Years & $12-18$ Years & $\begin{array}{l}18-45 \\
\text { Years }\end{array}$ & $\begin{array}{l}\text { Pearson's } \\
\text { Correlation Test }\end{array}$ & $\begin{array}{l}\text { Pearson's } \\
\text { Chi-Squared } \\
\text { Test }\end{array}$ \\
\hline \multicolumn{4}{|c|}{ False-Negative Clinical Findings (Marek -) } & \multirow{4}{*}{$\begin{array}{l}r=-0.010 \text { total } \\
\text { number versus } \\
\text { false-negative } \\
\text { clinical findings }\end{array}$} & \multirow{12}{*}{$\begin{array}{l}5.355 \times 10^{-} \\
40 \text { Pearson's } \\
\text { chi-squared } \\
\text { test }\end{array}$} \\
\hline \multicolumn{4}{|l|}{ Sex } & & \\
\hline Male & $\begin{array}{l}3 \\
(0.75 \%)\end{array}$ & 0 & 0 & & \\
\hline Female & $\begin{array}{l}3 \\
(0.75 \%)\end{array}$ & $5(1.25 \%)$ & $3(0.75 \%)$ & & \\
\hline \multicolumn{4}{|c|}{ False-positive clinical findings (Marek +) } & \multirow{4}{*}{$\begin{array}{l}r=0.951 \text { total } \\
\text { number versus } \\
\text { false-positive } \\
\text { clinical findings }\end{array}$} & \\
\hline \multicolumn{4}{|l|}{ Sex } & & \\
\hline Male & $17(4.24 \%)$ & $21(5.24 \%)$ & 0 & & \\
\hline Female & $10(2.49 \%)$ & $11(2.74 \%)$ & $\begin{array}{l}26 \\
(6.48 \%)\end{array}$ & & \\
\hline \multicolumn{4}{|c|}{ Positive clinical findings (Marek +) } & \multirow{4}{*}{$\begin{array}{l}r=0.996 \text { total } \\
\text { number versus } \\
\text { positive clinical } \\
\text { findings }\end{array}$} & \\
\hline \multicolumn{4}{|l|}{ Sex } & & \\
\hline Male & $35(8.73 \%)$ & $98(24.44 \%)$ & 0 & & \\
\hline Female & $22(5.49 \%)$ & $27(6.73 \%)$ & $\begin{array}{l}120 \\
(29.93 \%)\end{array}$ & & \\
\hline
\end{tabular}

We found a strong correlation $(r>0.95)$ for the distribution of the total number of examined patients (grouped by sex and age) versus false-positive clinical findings, and also for the total number of examined patients (grouped by sex and age) versus positive clinical findings (Table 3). Pearson's chisquared analysis showed no significant differences between the expected and observed frequencies of both the clinical and histological findings.

Based on these statistical results, we came to the following conclusions:

In children (aged 0-12, male/female) and in women of childbearing age (aged 12-45), we observed 14 $(3,46 \%)$ false negative clinical findings for the palpation sign.

In children and women of childbearing age, we observed a higher percentage of palpation sign positivity compared to false positivity (Table 3 ). The new palpation sign minimizes unindicated revisions of the abdominal cavity, serves as a reliable indicator for surgery and is suitable for the diagnosis of AA in atypical forms (i.e., in children and women of childbearing age) with a sensitivity of $95,57 \%$, a specificity of $95,78 \%$, a positive predictive value of $67,86 \%$, a negative predictive value of $99,50 \%$, a positive likelihood ratio of 24,28 , a negative likelihood ratio of 0,05 and an accuracy of $95,9 \%$. 


\section{Discussion}

In this study, we have proposed a new palpation sign for the diagnosis of atypical forms of AA (i.e., in children and women of childbearing age). Based on our experience and the statistical data $(r>0.95)$, the sign is not only effective for the diagnosis of atypical forms of $A A$, but also for the indication of surgery. The effectiveness of the new palpation sign was objectified by histological examination.

Anamnesis and clinical examination remain the primary diagnostic procedures for AA. Examination via palpation of the abdomen represents a key part of the clinical examination for AA. Abdominal palpation is a difficult skill to master in the clinical examination. Its effectiveness can be enhanced by understanding the clinical nature of each palpation sign and the ability to find synchronicity between each sign. This forms the cornerstone of proper AA diagnosis.

The main disadvantages of the original palpation signs (i.e.,McBurney, Alder, Blumberg- Shchetkin) include a considerable degree of subjectivity. Their effectiveness is based on a subjective evaluation of the degree of pain and contracture of the abdominal wall during palpation. Palpation of the pulsation of the iliac arteries, which is the main part of the new palpation sign, is an objective indicator that reduces the degree of subjectivity and ensures reproducibility. With a higher degree of objectivity, the sensitivity and specificity of the new palpation sign increases. The sensitivity of the new palpation sign is $95,57 \%$ and the specificity $95,78 \%$.

Imaging examinations (US and CT) are used to supplement diagnostic examinations. Overall sensitivity and specificity of US is $65,5-76 \%$ and $95 \%$ and for CT is $72-99 \%$ and $84 \%$, respectively $[25,36]$. Point-ofcare ultrasonography (POCUS) has proven to be a valuable diagnostic tool in diagnosing AA and has a positive impact on clinical decision-making [26]. The meta-analysis by Matthew Fields et al. found that the sensitivity and specificity for POCUS in diagnosing AA were $91 \%$ and $97 \%$, respectively. The positive and negative predictive values were $91 \%$ and $94 \%$, respectively [27]. POCUS, if performed by an experienced operator, should be considered the most appropriate first-line diagnostic tool in both women of childbearing age and children. In patients with atypical forms of AA, routine diagnostic laboratory workup for suspected AA should include WBC, the differential with the calculation of the absolute neutrophil count (ANC), neutrophil -to-lymphocyte ratio (NLR), C-reactive protein (CRP), red cell distribution width $[48,49]$ and urinalysis. Recently, ischemia-modified albumin (IMA) and procalcitonin levels have been used to determine the prediction of severity in AA patients $[28,29]$. A combination of clinical examination (with new palpation sign), laboratory tests, and US may significantly improve diagnostic sensitivity and specificity and eventually replace the need for CT scan in both women of childbearing age and children [30,37]. Recent studies from the Finnish group led by Salminen demonstrated that the diagnostic accuracy of contrast-enhanced low-dose CT is not inferior to standard CT in diagnosing AA or distinguishing between uncomplicated and complicated AA. However, the mean radiation dose of low-dose CT was significantly lower compared with standard CT (3.33 and $4.44 \mathrm{mSv}$, respectively) (31). 
Pain in the right hypogastrium in women of childbearing age still presents a diagnostic problem. The incidence of incorrect diagnoses is as high as 33\% [32]. AA is most often mistaken for pelvic inflammatory disease (PID), gastroenteritis, or urinary tract infection. The typical cause of a diagnostic mistake is an atypical type of pain, such as a mostly diffuse, colic, bilateral pain in the abdomen or right adnexa. The typical transition of visceral pain to somatic pain is absent $[6,7,8]$. Delayed AA diagnosis may result in perforation of the appendix, leading to tragic consequences for women of childbearing age in terms of sterility $[11,12,13]$.

The advantage of the new palpation sign is its viscerosomatic character. Thanks to the visceral reflex arc, the sign enables the diagnosis of AA even before the onset of somatic pain with peritoneal symptoms, thus eliminating one of the important factors that contributes to diagnostic mistakes in women of childbearing age [24].

Laparoscopic appendectomy is indicated in women with suspected AA with positive clinical examination (new palpation sign), high US (POCUS) suspicion and negative gynaecological examination. If the clinical examination (new palpation sign) is negative, with high US (POCUS) suspicion we prefer diagnostic +/therapeutic laparoscopy (Fig. 3).

Diagnostic laparoscopy allows direct visualisation of the intra-abdominal organs with low morbidity and may find unexpected concomitant pathologies. Larsson et al prospectively randomised 110 women of childbearing age with right lower abdominal pain and suspected appendicitis into open or laparoscopic appendectomy. They found that among the women with a normal appendix, a gynaecological diagnosis was found in $73 \%$ after laparoscopy, as compared with $17 \%$ after open surgery [44]. Lim et al found that the diagnostic accuracy of the diagnostic laparoscopy compared with other imaging methods (US,CT), was higher. The women of childbearing age had a particularly high specificity (95-100\%) for diagnostic laparoscopy compared with imaging groups (US,CT) [45]. The difficulty with laparoscopy for the diagnosis of acute appendicitis is that the negative appendectomy rate is higher than open appendectomy because of the absence of tactile feedback. Kraemer et al. found that the negative rates were $22 \%$ for laparoscopic appendectomy and $15 \%$ for open appendectomy [47].

Garbarino and Shimi found that routine use of diagnostic laparoscopy in women of this age significantly reduced the negative appendectomy rate to $5 \%$, compared with selective use of diagnostic laparoscopy in this group of patients (with typical presentation of RLQ), which reduced the negative appendectomy rate to $31 \%$ (insignificant) [46].

Our study revealed that the negative appendectomy rate was 9,22\%. False negative clinical findings occurred in $8(2,0 \%)$ women of childbearing age, of which 3 women had a retrocecal position of the appendix, 4 women had a BMl $>25 \mathrm{~kg} / \mathrm{m} 2$ and 1 woman had a subhepatically located caecum and appendicitis due to anomalies in fetal gut rotation.

We do not indicate conservative treatment in this group of patients due to the risk of a two-stage rupture of the appendix and recurrence of the disease $(12,2-30 \%$ within 1 year) $[33,34]$. 
The diagnosis of AA in children is also problematic. In particular, younger children are not able to adequately assess and describe their health problems. In such cases, children are often bad-tempered and refuse to sleep, eat, or drink. Children typically do not respond to caressing and are not satisfied in their mother's arms. In most cases, the mother suspects that the child only has a stomach ache and is unable to substantiate the problem exactly. In such cases, the recommendation of Professor Tošovský applies: "We must never contradict the mother's opinion due to our professional knowledge. It is the quickest way to a mistake" [35]. In contrast to school children and adolescents, younger children do not present the classical clinical picture with initial anorexia and peri-umbilical pain that migrates in the right fossa iliaca, vomiting and fever [15]. According to that, in our series, the only constant symptom on admission was abdominal pain that was diffuse in the majority of cases. Fever, anorexia and transit alteration were not observed in all patients. We try to identify palpable pain in the right hypogastrium and the presence of peritoneal irritation, which represent a "sign over signs". Some degree of experience is needed to differentiate the protective muscle tension of the abdominal wall (peritoneal irritation) from the free contraction of the abdominal wall in children due to their fear. The new palpation sign removes this disadvantage. Its essence is the palpation of iliac artery pulsation, not a subjective assessment of the pain and reflex tension of the abdominal muscles. Palpation of the pulsation of the iliac arteries is an objective indicator that is not affected by the child's restlessness.

The analysis by Yasmine Lounis et al. found that the sensitivity for first abdominal sonography diagnosing AA in children was $65,5 \%$. In most of children in whom abdominal ultrasound was negative, appendix was either not- or incompletely visualized. A common cause for that is ectopic position of the appendix [36].

Nevertheless, new palpation sign, abdominal ultrasound and laboratory tests should, due to the possibility to easily repeat examinations and a sufficient degree of objectivity remain the first choice and the most frequently performed examinations for the diagnosis of appendicitis in the pediatric population. By combining these three examinations, we can also generate a diagnostic scoring system. We consider the positivity of a new palpation sign in the diagnosis of AA in children to be paramount. Nevertheless, in cases of clinical doubt, ultrasonography may improve the diagnosis and reduce the negative laparotomy rate. The rate of negative appendectomy in children reported in the surgical literature ranges from 8 to $33 \%[40]$.

This study revealed that the negative appendectomy rate was $6,72 \%$. False negative clinical findings occurred in $6(1,48 \%)$ children, of which 4 children had a retrocecal position of the appendix.

Acute appendectomy is indicated in children with suspected AA with positive clinical examination (new palpation sign) and a positive US (POCUS), without the need for a CT scan or MRI. If the clinical examination (new palpation sign) is negative, with US (POCUS) suspicion, the decision to use further imaging studies, observe, or discharge to home is based on the treating physician's clinical judgment. We recommend conservative treatment (antibiotic therapy) with patient observation (repeated clinical and 
POCUS examination). MRI or diagnostic +/- therapeutic laparoscopy is indicated for failure of conservative treatment (Fig. 4).

Few studies on this subject demonstrated no difference in the rate of postoperative complications between children who underwent appendectomy after failure of conservative (antibiotic) therapy and those who were treated surgically upon first presentation of $A A[41,42,43]$. We came to the similar results.

The diagnostic performance of staged algorithms involving US followed by conditional MRI imaging for the diagnostic workup of pediatric AA has proven to be high (98.2\% sensitive and $97.1 \%$ specific) [38]. MRI is a feasible alternative to CT for secondary imaging in AA in children, and it can differentiate perforated from non-perforated AA with a high specificity [39].

This study has several limitations. First, the clinical examinations in this study were performed by a group of experienced surgeons (residents). It is questionable whether novice surgeons would also achieve the same level of effectiveness in diagnosing AA. Second, the new palpation sign has not been directly compared with imaging examinations. The reason is an unrepresentative control group of patients examined ultrasonographically in our study due to:

- using qualitatively different types of ultrasonographic instruments

- radiologists with varying degrees of ultrasonographic experience and knowledge of secondary AA ultrasonographic signs

- inability to identify the appendix in all patients.

CT examination was indicated relatively rarely due to concerns related to the hazards of ionizing radiation. Finally, the retrospective nature of the study is also a limitation. These limitations may form the basis for subsequent studies.

\section{Conclusion}

In conclusion, this study offers surgeons a new palpation sign as a reliable tool for diagnosing atypical forms of AA. It is aimed principally at the medical practitioners in different parts of the world and in a state of emergency (Covid-19 pandemic, wars, etc.) where the diagnostic facilities and technological resources are limited. We state that the new palpation sign is effective for the diagnosis of atypical forms of AA (i.e., in children and women of childbearing age); however, obesity reduces its efficacy. The sign is reliable for indicating urgent surgical intervention. Thorough and repeated palpation remains the basis of AA diagnosis. The surgeon's combination of expertise, experience, and humility turns diagnosing AA into a surgical art.

\section{Abbreviations}

AA: Acute Appendicitis 
US: Ultrasound

CT: Computer Tomography

POCUS: Point-of-care ultrasonography

ANC: Absolute neutrophil count

CRP: C- reactive protein

IMA: Ischemia-modified albumin

PID: Pelvic inflammatory disease

MRI: Magnetic resonance imaging

WBC: White blood cell

RLQ: Right lower quadrant of the abdomen

BMl: Body Mass Index

NLR: Neutrophil-to- lymphocyte ratio

ATB: Antibiotics

\section{Declarations}

\section{Acknowledgements}

This article is dedicated, with love, to my parents. They were always there, by Vitezslav Marek.

\section{Funding}

This research received no external funding.

\section{Author information}

\section{Affiliations}

Department of Surgical Oncology, St. Elizabeth Hospital, Medical School of Comenius University, 81250 Bratislava, Slovak Republic

Vitezslav Marek, Stefan Durdik

Department of Anaesthesiology and Intensive Medicine, St. Elizabeth Hospital, Medical School of Comenius University, 81250 Bratislava, Slovak Republic 
Roman Zahorec

\section{Contributions}

Conceptualisation: V.M., R.Z.; methodology: V.M., S.D.; software: S.D.; validation V.M., R.Z., S.D..; formal analysis: V.M.; investigation: V.M., R.Z.; data curation: V.M., S.D.; writing-original draft preparation, V.M.; writing-review and editing V.M., S.D.; supervision: R.Z.; All authors have read and agreed to the published version of the manuscript.

\section{Corresponding author}

\section{Correspondence to Vitezslav Marek, vitezslav.marek@gmail.com or vmarek@ousa.sk}

\section{Ethics declarations}

\section{Ethics approval and consent to participate}

Informed consent was obtained from all individual participants included in the present study. All procedures performed in this study involving human participants were in accordance with the ethical standards of the institution and with the 1964 Helsinki declaration and its later amendments or comparable ethical standards.

\section{Consent for publication}

Not applicable.

\section{Competing interests}

The authors declare no conflicts of interest.

\section{References}

1. Jirasek, A. Acute Abdomen; Melantrich: Praha, Czechia, 1939; pp. 110-115.

2. Alvarado A. How to improve the clinical diagnosis of acute appendicitis in resource limited settings. World J Emerg Surg. 2016; 11, 16. https://doi.org/10.1186/s13017-016-0071-8

3. Ekbatani MS, Hassani SA, Tahernia L, Yaghmaei B, Mahmoudi S, Navageian A, Rostamyan M, Zamani F, Manishi S. Atypical and novel presentations of Coronavirus Disease 2019: a case series of three children. British Journal of Biomedical Science. 2021; 78,1. https://doi.org/10.1080/09674845.2020.1785102

4. Wang Z, Ye J, Wang Y, Liu Y, Diagnostic accuracy of pediatric atypical appendicitis Three case reports. Medicine (Baltimore). 2019; 98(13), doi: 10.1097/MD.0000000000015006

5. Becker T, Kharbanda AB, Bachur R. Atypical Clinical Features of Pediatric Appendicitis. Academic Emergency Medicine.2007; 14(2):124-9. DOI: 10.1197/j.aem.2006.08.009 
6. Jearwattanakanok K,Yamada S, Suntornlimsiri W, Smuthtai W, Patumanond J. Clinical scoring for diagnosis of acute lower abdominal pain in female of reproductive age. Emergency Medicine International.2013, 6. DOI: 1155/2013/730167

7. Morishita K, Gushimiyagi M, Hashiguchi M, Stein GH, Tokuda Y. Clinical prediction rule to distinguish pelvic inflammatory disease from acute appendicitis in women of childbearing age. American Journal of Emergency Medicine.2007; 25 (2): 152-157.

8. Morse BC, Roettger RH, Kalbaugh CA, Blackhurst DW, Hines WB Jr.. Abdominal CT scanning in reproductive-age women with right lower quadrant abdominal pain: does its use reduce negative appendectomy rates and healthcare costs? American Surgeon.2007; 73, 6, 580-584.

9. Basta MW, Morton NE, Mulvihill JJ. Inheritance of acute appendicitis: Familial aggregation and evidence of polygenic transmission. J. Hum. Genet.1990; 46, 377-382.

10. Brown TW, McCarthy ML, Kelen GD. An epidemiologic study of closed emergency department malpractice claims in a national database of physician malpractice insurers. Emerg. Med.2010; 17, 553-560.

11. Elraiyah T, Hashim Y, Elamin M, Erwin PJ, Zarroug AE. The effect of appendectomy in future tubal infertility and ectopic pregnancy: a systematic review and meta-analysis. J Surg Res. 2014;192:368374.e1doi: 10.1016/j.jss.2014.08.017.

12. Becker WM, Silver S, Seufert R, Muensterer OJ. The Association of Appendectomy, Adhesions, Tubal Pathology, and Female Infertility. JSLS. 2019; 23(1): e2018.00099.doi: 10.4293/JSLS.2018.00099

13. Wei L, MacDonald T, Shimi S. Association between prior appendectomy and/or tonsillectomy in women and subsequent pregnancy rate: a cohort study. Fertil Steril. 2016; 106:1150-1156.

14. Rothrock SG, Pagane J. Acute appendicitis in children: Emergency department diagnosis and management. Emerg. Med.2000, 36, 39-51.

15. Almaramhy $\mathrm{HH}$. Acute appendicitis in young children less than 5 years: review article. Ital $\mathrm{J}$ Pediatr. 2017;43:15. https://doi.org/10.1186/s13052-017-0335-2.

16. Pogorelic Z, Domjanovic J, Jukic M, Pericic TP. Acute appendicitis in children younger than five years of age: diagnostic challenge for pediatric surgeons. Surg Infect. 2019;21(3):239. https://doi.org/10.1089/sur.2019.175.

17. Pogorelic Z, Buljubasic M, Susnjar T, Jukic M, Pericic TP, Juric I. Comparison of open and laparoscopic appendectomy in children: a 5-year single center experience. Indian Pediatr. 2019;56:299-303.

18. Pogorelic Z, Silov N, Jukic M, Elezovic Baloevic S, Peričić TP. Ertapenem monotherapy versus gentamicin plus metronidazole for perforated appendicitis in pediatric patients. Surg Infect. 2019;20:625-30. https://doi. org/10.1089/sur.2019.025.

19. van den Boom AL, Gorter RR, van Haard PM, Doornebosch PG, Heij HA, Dawson I. The impact of disease severity, age and surgical approach on the outcome of acute appendicitis in children. Pediatr Surg Int. 2015;31:339-45. https://doi.org/10.1007/s00383-015-3677-0. 
20. Bansal S, Banever GT, Karrer FM, Partrick DA. Appendicitis in children less than 5 years old: influence of age on presentation and outcome. Am J Surg. 2012;204:1031-5. https://doi.org/10.1016/j.amjsurg.2012.10.003.

21. Naiditch JA, Lautz TB, Daley S, Pierce MC, Reynolds M. The implications of missed opportunities to diagnose appendicitis in children. Acad Emerg Med. 2013;20:592-6. https://doi.org/10.1111/acem.12144.

22. Nance M, Adamson WT, Hedrick HL. Appendicitis in the young child: A continuing diagnostic challenge. Emerg. Care2000, 16, 160-162.

23. Ünlü C, de Castro SMM, Tuynman JB, Wüst AF, Steller EP, Van Wagensveld BA. Evaluating routine diagnostic imaging in acute appendicitis. International Journal of Surgery.2009, 5, 451-455.

24. Marek V, Zahorec R, Durdik S. Acute appendicitis: Clinical anatomy of the new palpation sign. Anat.2020, 1-6. Wiley Online Library https://doi.org/10.1002/ca.23684

25. Chang ST, Jeffrey RB, Olcott EW. Three-step sequential positioning algorithm during sonographic evaluation for appendicitis increases appendiceal visualization rate and reduces CT use. Am J Roentgenol. 2014;203:1006-12.

26. Di Saverio S, Podda M, De Simone B. Diagnosis and treatment of acute appendicitis: 2020 update of the WSES Jerusalem guidelines. World J Emerg Surg 15, 27 (2020). https://doi.org/10.1186/s13017020-00306-3

27. Fields JM, Davis J, Alsup C. Accuracy of point-of-care ultrasonography for diagnosing acute appendicitis: a systematic review and meta-analysis. Acad Emerg Med. 2017;24:1124-36.

28. Kılıç MÖ, Güldoğan CE, Balamir İ. Ischemia-modified albumin as a predictor of the severity of acute appendicitis. Am J Emerg Med. 2017;35:92-5.

29. Cui W, Liu H, Ni H. Diagnostic accuracy of procalcitonin for overall and complicated acute appendicitis in children: a meta-analysis. 2019; Ital J Pediatr45, https://doi.org/10.1186/s13052-0190673-3

30. Reddy SB, Kelleher M, Bokhari SAJ. A highly sensitive and specific combined clinical and sonographic score to diagnose appendicitis. J Traum Acute Care Surg. 2017;83:643-9.

31. Sippola S, Virtanen J, Tammilehto V. The accuracy of low-dose computed tomography protocol in patients with suspected acute appendicitis: the OPTICAP study. Ann Surg. 2018;1.

32. Rothrock SG, Green MS, Dobson M, Colucciello SA, Simmons MC. Misdiagnosis of appendicitis in nonpregnant women of childbearing age. The Journal of Emergency Surgery.1995; 13, 1-8.

33. Lundholm K, Hansson-Assarsson J, Engström C, Iresjö BM. Long-term results following antibiotic treatment of acute appendicitis in adults. World J Surg.2017; 41, 2245-2250.

34. Al-Mulhim AS. Readmission after antibiotic management of uncomplicated acute appendicitis in adults: prospective study. European Journal of Trauma and Emergency Surgery.2020;46: 841-846 DOI: 10.1007/s00068-018-1038-0 
35. Tošovsky VV. Náhle Přihody Břišní u dětí Včasná Diagnostika; Avicenum Grada Press: Praha, Czechia, 1996; pp. 51-64.

36. Lounis Y, Hugo J, Demarche M. Influence of age on clinical presentation, diagnosis delay and outcome in pre-school children with acute appendicitis. BMC Pediatr. 2020; 20: https://doi.org/10.1186/s12887-020-02053-5

37. Rentea RM, Peter SDS, Snyder CL. Pediatric appendicitis: state of the art review. Pediatr Surg Int. 2017;33:269-83. https://doi.org/10.1007/s00383-016-3990-2.

38. Dibble EH, Swenson DW, Cartagena C. Effectiveness of a staged US and unenhanced MR imaging algorithm in the diagnosis of pediatric appendicitis. Radiology. 2018;286:1022-9.

39. Rosenbaum DG, Askin G, Beneck DM, et al. Differentiating perforated from non-perforated appendicitis on contrast-enhanced magnetic resonance imaging. Pediatr Radiol. 2017;47:1483-90.

40. Saleem MI, and Al-Hashmey AM. Appraisal of the modified Alvarado score for acute Saudi Med J 2004 Sep; 25(9): 1229-31.

41. Svensson JF, Patkova B, Almstrom M, et al. Nonoperative treatment with antibiotics versus surgery for acute nonperforated appendicitis in children: a pilot randomized controlled trial. Ann Surg 2015;261:67-71.

42. Minneci PC, Mahida JB, Lodwick DL, et al. Effectiveness of patient choice in nonoperative vs surgical manag ment of pediatric uncomplicated acute appendicitis. JAMA Surg 2016;151:408-15.

43. Tanaka $Y$, Uchida $H$, Kawashima $H$, et al. Long-term outcomes of operative versus nonoperative treatment for uncomplicated appendicitis. J Pediatr Surg 2015;50:1893-7.

44. Larsson PG, Henriksson G, Olsson M, et al. Laparoscopy reduces unnecessary appendicectomies and improves diagnosis in fertile women. A randomized study. Surg Endosc 2001; 15:200-2.

45. Lim GH, Shabbir A, So JB. Diagnostic laparoscopy in the evaluation of right lower abdominal pain: A one-year audit. Singapore Med J 2008;49:451-453.

46. Garbarino S, Shimi SM. Routine diagnostic laparoscopy reduces the rate of unnecessary appendicectomies in young women. Surg Endosc 2009;23:527-533.

47. Kraemer M, Ohman C, Leoppert R, Yang O. Macroscopic assessment of the appendix at diagnostic laparoscopic is realiable. Surgical Endoscopy 2000;14(7):625-633.

48. Toktas $\mathrm{O}$, Aslan M. Mean platelet volume, red cell distribution width, neutrophil to lymphocyte ratio and platelet to lymphocyte ratio in the diagnosis of acute apendicitis. East J Med 2017; 22(1): 5-9.

49. Celik B., Nalcacioglu H., Ozcatal M., Torun Y. A. Role of neutrophil-to-lymphocyte ratio and platelet-tolymphocyte ratio in identifying complicated appendicitis in the pediatric emergency department. Ulus Travma Acil Cerrahi Derg, 2019; 25(3): 222-228.

\section{Figures}




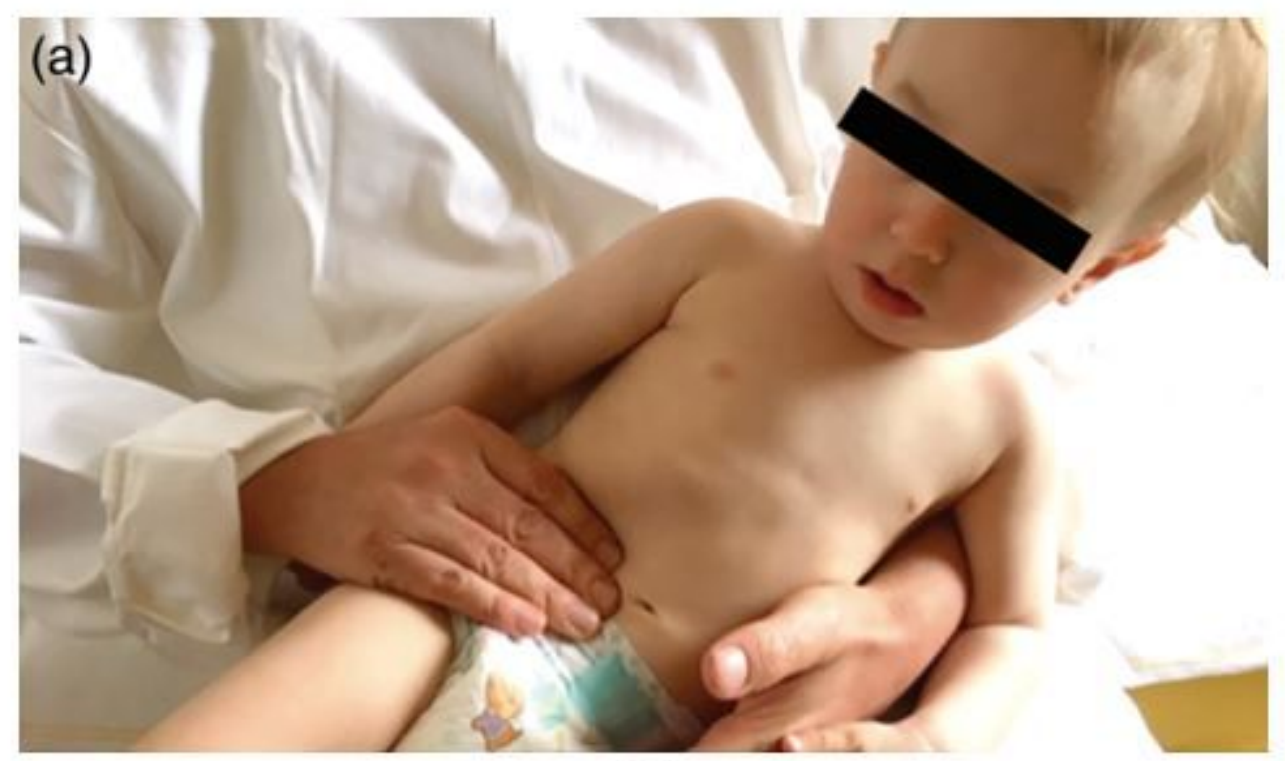

(a)

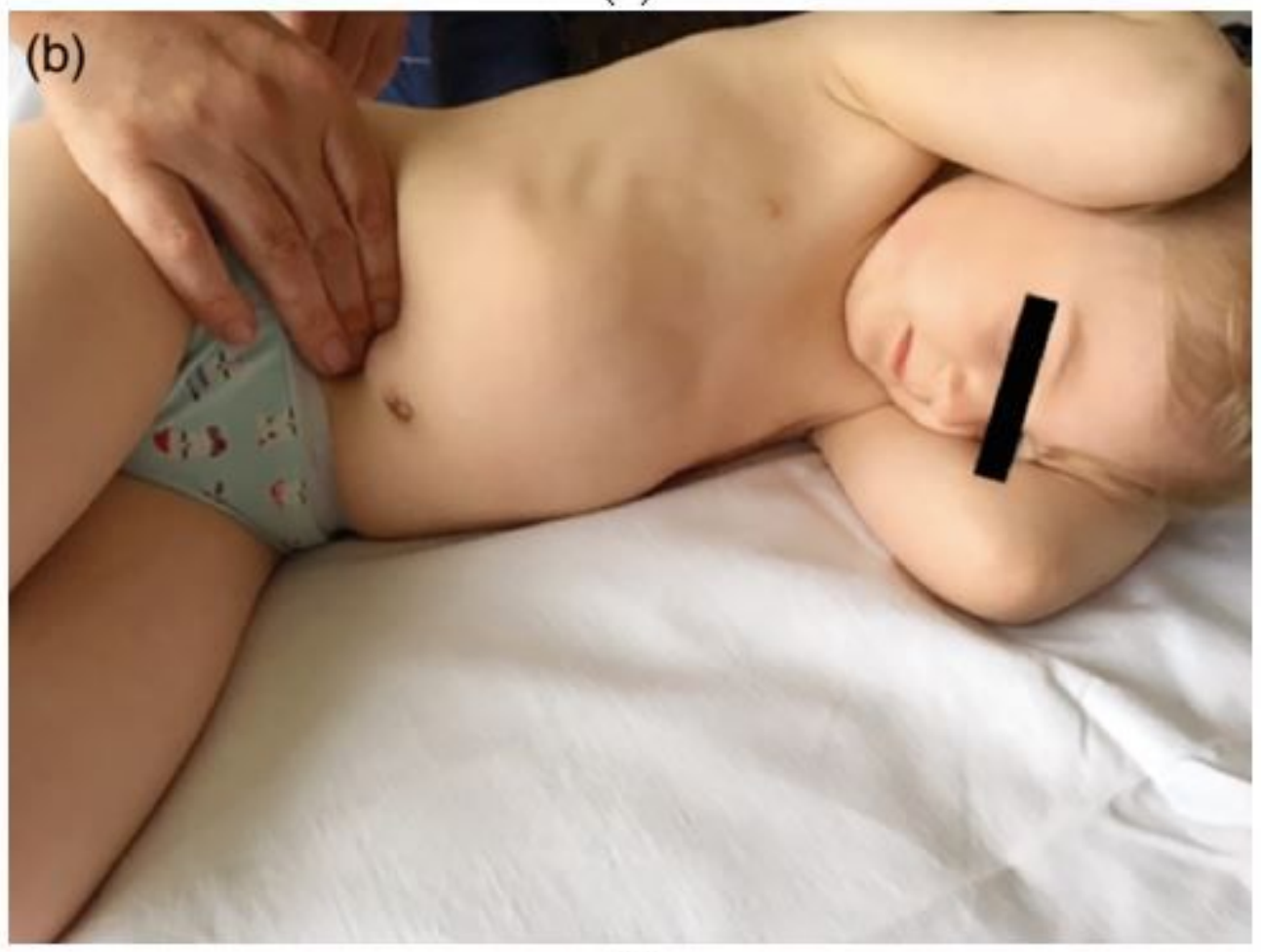

(b)

\section{Figure 1}

(a) Examination of a child younger than two years of age. Position of the "pietá di Michelangelo" (authors archive). (b) Examina-tion of a child older than two years of age (authors archive). 


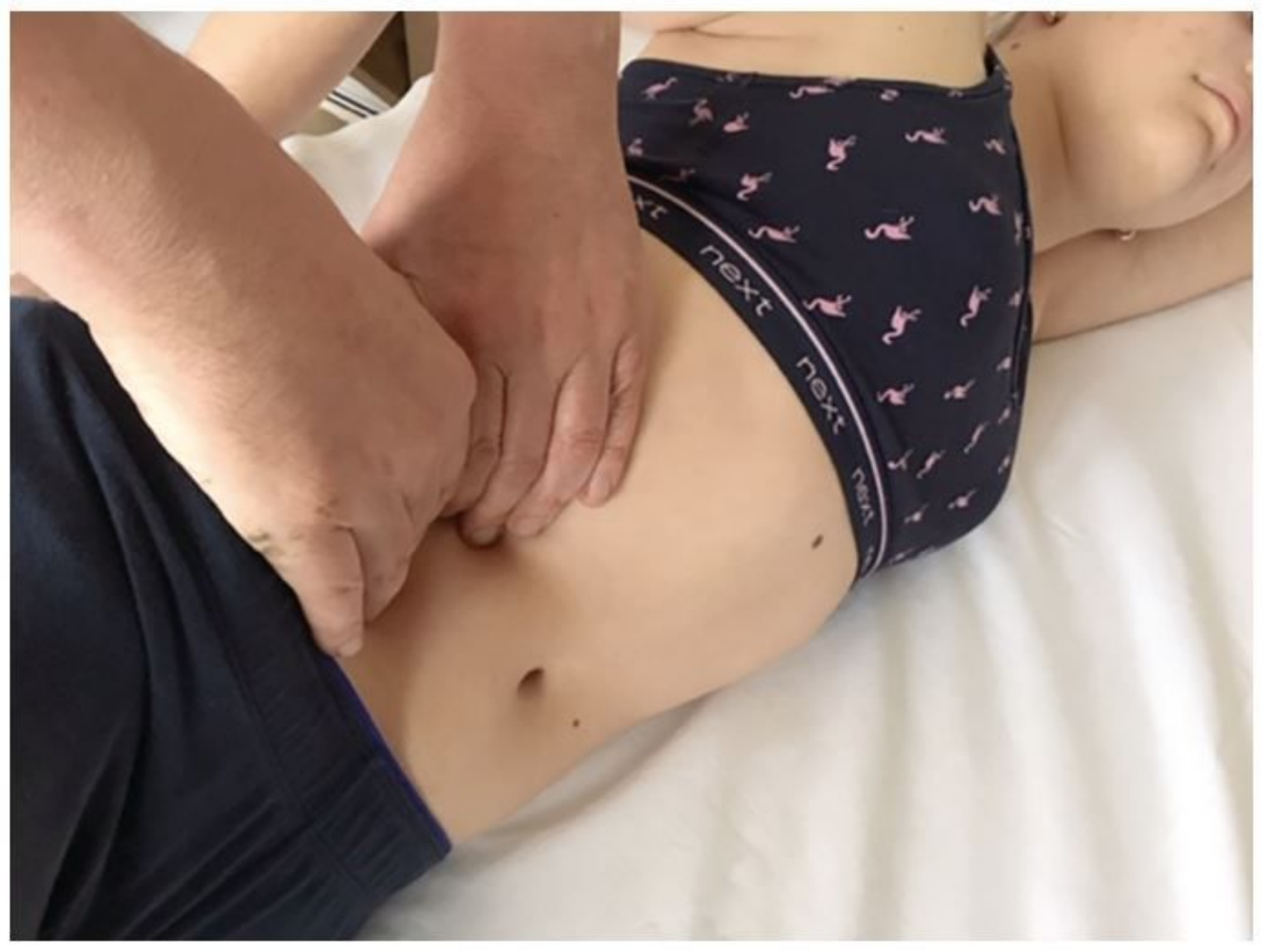

Figure 2

Examination of a woman of childbearing age (authors archive). 


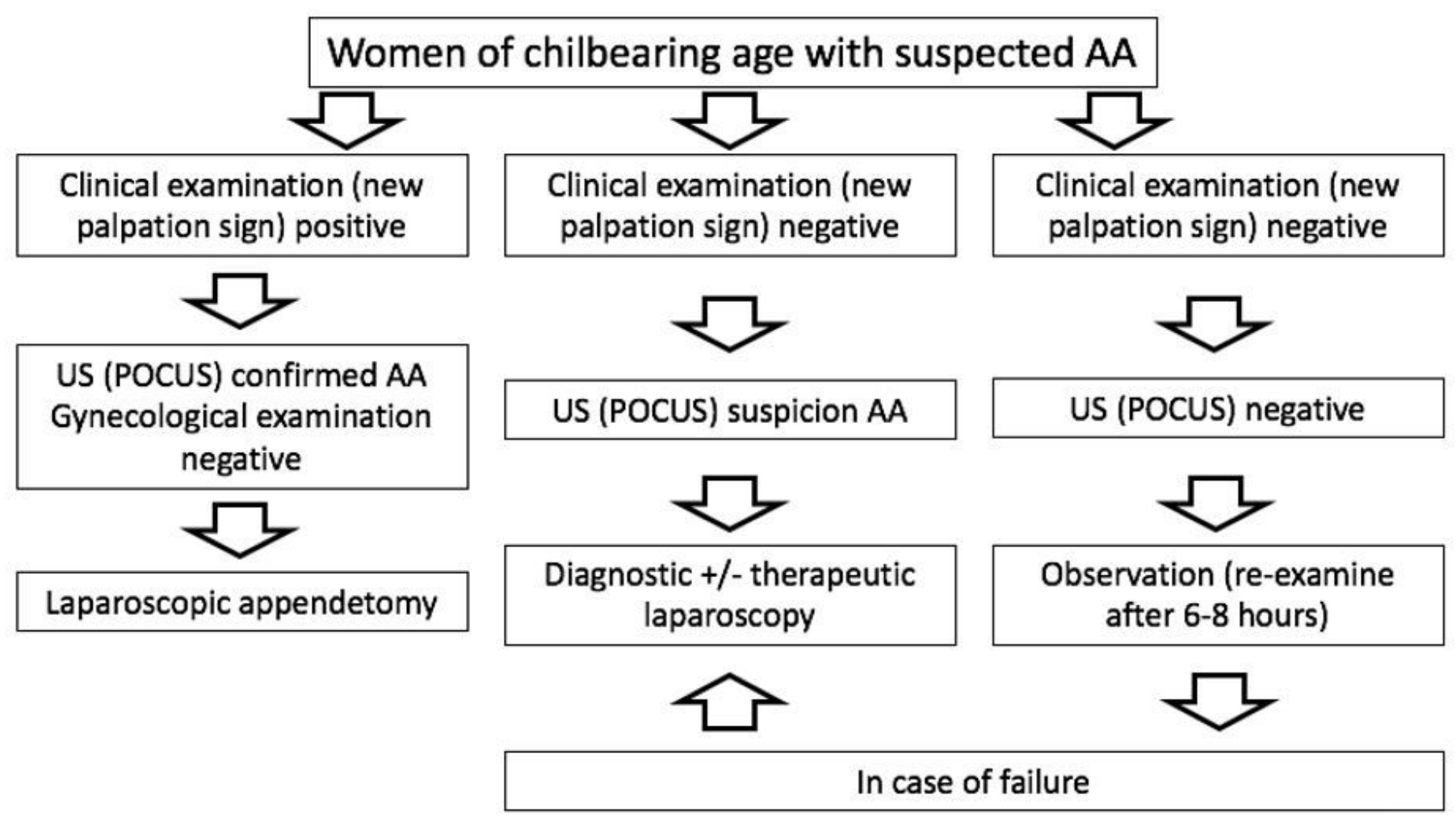

Figure 3

Algorithm for diagnosis and treatment of women of childbearing age with suspected AA (authors archive). 


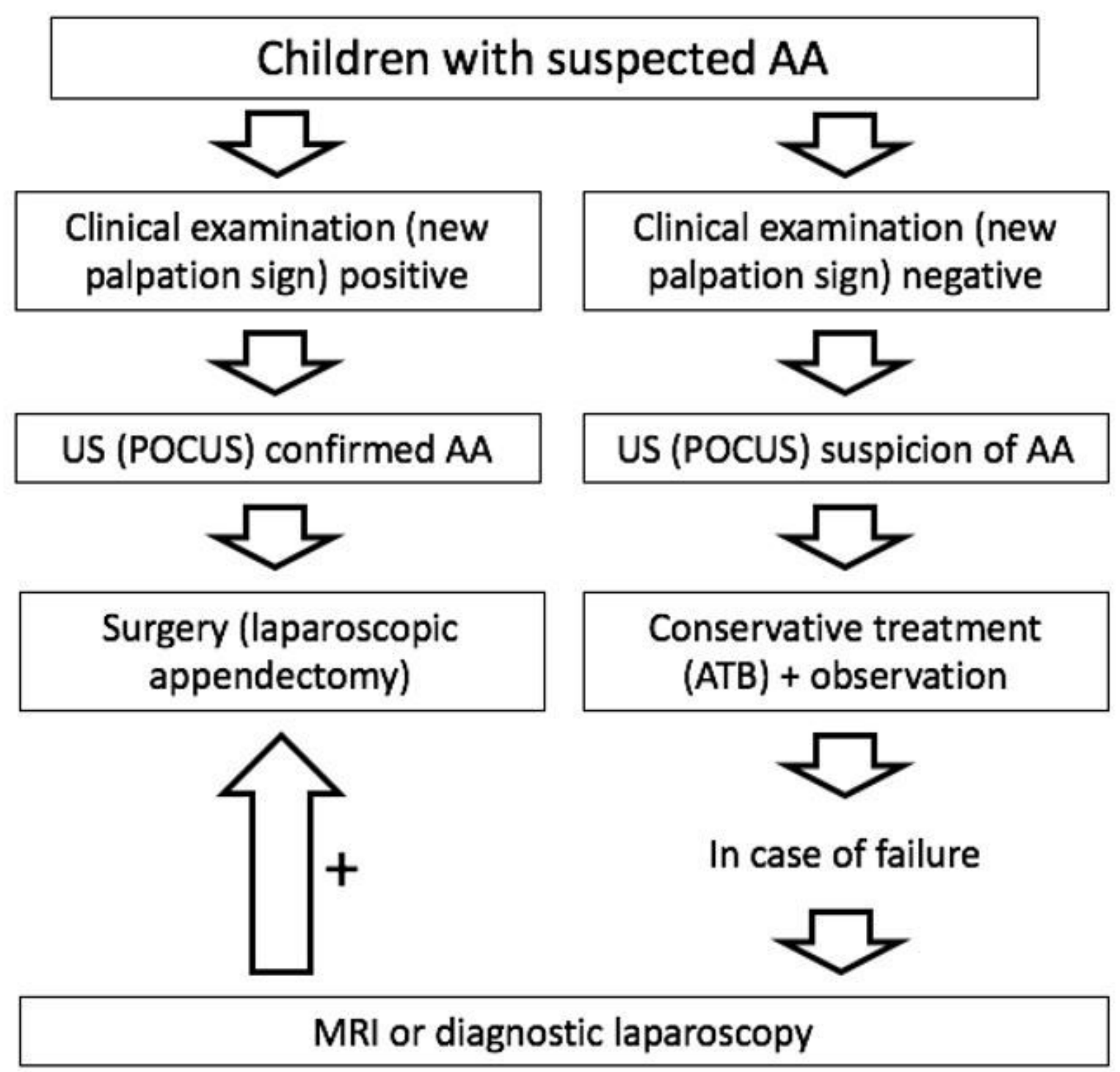

Figure 4

Algorithm for diagnosis and treatment of children with suspected AA (authors archive). 